\begin{tabular}{|c|c|}
\hline $\begin{array}{l}\text { Дзюбан Оксана Володимирівна - старший викла- } \\
\text { дач, Чорномо́рський націона́льний університе́т і́ме- } \\
\text { ні Петра́ Моги́ли (Миколаїв,Україна) }\end{array}$ & $\begin{array}{l}\text { Dziuban Oksana Volodymyrivna - lecturer, Petro } \\
\text { Mohyla Black Sea National University (Mykolaiv, } \\
\text { Ukraina) }\end{array}$ \\
\hline \multicolumn{2}{|l|}{ https://orcid.org/0000-0002-7417-5650 } \\
\hline $\begin{array}{l}\text { Кураса Геннадій Олександрович - старший } \\
\text { викладач, Чорномо́рський націона́льний універ- } \\
\text { сите́т і́мені Петра́ Моги́ли (Миколаїв, Україна) }\end{array}$ & $\begin{array}{l}\text { Kurasa Hennadii Oleksandrovych }- \text { lecturer, Petro } \\
\text { Mohyla Black Sea National University (Mykolaiv, } \\
\text { Ukraina) }\end{array}$ \\
\hline \multicolumn{2}{|l|}{ https://orcid.org/0000-0001-5834-4509 } \\
\hline $\begin{array}{l}\text { Бондаренко Олег Володимирович - викладач, } \\
\text { Чорномо́рський націона́льний університе́т і́мені } \\
\text { Петра́ Моги́ли (Миколаїв,Україна) }\end{array}$ & $\begin{array}{l}\text { Bondarenko Oleh Volodymyrovych - lecturer, Petro } \\
\text { Mohyla Black Sea National University (Mykolaiv, } \\
\text { Ukraina) }\end{array}$ \\
\hline & \\
\hline
\end{tabular}

УДК 37.042.1:615.825.1

doi: 10.15330/fcult.33.34-39

Лідія Доцюк, Олена Гауряк

\title{
ВПЛИВ АДАПТИВНОЇ КОРЕКЦЙНО-РОЗВИВАЮЧОЇ ПРОГРАМИ НА ФУНКЦІОНАЛЬНИЙ СТАН ПІДЛІТКІВ ІЗ ЗАТРИМКОЮ ПСИХІЧНОГО РОЗВИТКУ
}

\begin{abstract}
Розробка методів корекції рухових порушень у школярів із затримкою психічного розвитку може бути виділена як один із пріоритетних напрямків адаптивної фізичної культури як форми впливу на рухову сферу дітей, підвищення резистентності та самоконтролю. Метою дослідження було вивчення впливу методики адаптивної корекційно-розвиваючої гімнастики на функціональний стан підлітків із затримкою психічного розвитку. Адаптивно-корекційна розвиваюча гімнастика включала набір комплексу процедур, що включав застосування тілесно-орієнтованих вправ і самомасажу, використання ігор та вправ для розвитку психомоторики, психокорекиійні ігри, дихальні вправи. Показано, щзо заняття $з$ адаптивної корекційно-розвиваючої гімнастики призводять до істотного покращення показників морфо-функиіонального стану та зниження рівня стресу.
\end{abstract}

Ключові слова: затримка психічного розвитку, адаптивна фізична культура, функціональний стан організму.

Despite the prevalence of physical therapy methods in the medical rehabilitation of patients with somatic diseases, in some areas of modern medicine insufficient attention is paid to the development of adequate methods for the application of therapeutic physical culture. the development of methods for correction of motor disorders in schoolchildren with a delay in mental development can be highlighted as one of the priority areas of adaptive physical culture as a form of influence on the motor sphere of children, correction of motor insufficiency, rehabilitation of motor disorders, increase of resistance and self-control [11]. The solution to the problem of the integration and socialization of children with mental retardation in the life of modern society is mainly in the field of regenerative medicine, therapeutic and adaptive physical culture and is associated with the development of new therapeutic and practical and restorative technologies in order to restore the functional reserves of the body, compensate for lost functions and increase the level of health and quality of life of people with disabilities.

The purpose of the study was to study the influence of the method of adaptive correction-developing gymnastics on the functional state of adolescents with a delay in mental development. A set of research methods was used to solve the set tasks, including theoretical analysis and generalization of data of scientific and methodical literature; observation; methods of assessing the morphofunctional state, motor readiness, psychoemotional state; pedagogical experiment: mathematical and statistical processing of experimental data.

It is shown that classes on adaptive correction-developing gymnastics lead to a significant improvement in the indicators of morphofunctional status. Under the influence of an adaptive correction-development program, the number of students with a delay in the mental development of major groups, experiencing varying degrees of stress, greatly decreases.

Key words: mental retardation, adaptive physical culture, functional state of the organism. 
Постановка проблеми й аналіз результатів останніх досліджень. Застосування засобів фізичної реабілітації з лікувальною і профілактичною метою традиційно широко використовується при комплексному лікуванні та реабілітації в лікарнях, поліклініках, санаторіях, оздоровчих центрах і їх правильне застосування сприяє зміцненню функціональних можливостей і фізичних якостей організму, відновленню порушеної працездатності і повернення до нормальної життєдіяльності, дозволяє домогтися соціальної реабілітації $[3,4]$. Незважаючи на поширеність методів фізичної терапії у медичній реабілітації хворих і з соматичними захворюваннями, в деяких областях сучасної медицини недостатня увага приділяється розробці адекватних методів застосування методів лікувальної фізичної культури [5]. Повною мірою це відноситься до проблеми реабілітації дітей із затримкою психічного розвитку, хоча останнім часом встановлено, що швидка стомлюваність, коливання працездатності, нестійкість емоційно-вольової сфери у цій категорії пацієнтів зазвичай супроводжуються зниженими показниками фізичного розвитку і фізичної підготовленості [1]. Виявлено, що у них не сформовані сенсомоторні, інтелектуальні, мовні, емоційні передумови до різних видів діяльності [4]. У той же час, якщо питання клініки і діагностики затримки психічного розвитку дітей вивчені досить докладно [1], то дані про вплив фізичних навантажень на функціональний стан організму у цих пацієнтів представлені лише в поодиноких дослідженнях [5].

Проте, розробка методів корекції рухових порушень у школярів із затримкою психічного розвитку може бути виділена як один із пріоритетних напрямків адаптивної фізичної культури як форми впливу на рухову сферу дітей, корекції рухової недостатності, реадаптації рухових порушень, підвищення резистентності та самоконтролю [2]. Рішення проблеми інтеграції та соціалізації дітей із затримкою психічного розвитку в житті сучасного суспільства знаходиться головним чином в галузі відновлювальної медицини, лікувальної та адаптивної фізичної культури і пов'язане з освоєнням нових лікувально-практичних та відновлювальних технологій для відновлення функціональних резервів організму, компенсації втрачених функцій і підвищення рівня здоров'я і якості життя осіб із обмеженими можливостями.

Мета дослідження - вивчення впливу адаптивної корекційно-розвиваючої гімнастики на функціональний стан підлітків із затримкою психічного розвитку.

Методи й організація дослідження. Для вирішення поставлених завдань використовувався комплекс методів дослідження, що включали теоретичний аналіз і узагальнення даних науково-методичної літератури; спостереження; методи оцінки морфофункціонального стану, рівня стресу; педагогічний експеримент, математико-статистична обробка експериментальних даних.

У дослідженні взяло участь 14 підлітків із затримкою психічного розвитку 12-16 років (8 хлопчиків і 6 дівчаток) і 15 підлітків (9 хлопчиків і 6 дівчаток) із нормальним психічним розвитком того ж віку. Всі діти знаходилися в стандартних умовах педагогічного процесу, в межах якого проводилися організовані заняття фізичною культурою та корекційною гімнастикою, а також психокорекційні процедури. Частина з них 7 осіб (4 хлопчиків і 3 дівчаток) склали групу порівняння та 7 дітей (4 хлопчики і 3 дівчаток) увійшли в основну дослідницьку групу, яка додатково отримувала комплекс адаптивно-корекційних розвиваючих технологій. До контрольної групи увійшли 15 підлітків (9 хлопчиків і 6 дівчаток) з нормальним психічним розвитком того ж віку. Тривалість спостереження та застосування адаптивно-корекційної розвиваючої гімнастики становила 6 місяців, після чого проводилися порівняльні дослідження стану психофізичного статусу підлітків основної та контрольної групи. Адаптивно-корекційна розвиваюча гімнастика включала набір комплексу процедур, що включав застосування 
тілесно-орієнтованих вправ і самомасажу, використання ігор та вправ для розвитку психомоторики, психокорекційні ігри, дихальні вправи.

Функціональне тестування проводилося за загальноприйнятими методиками. Здійснювався підрахунок частоти серцевих скорочень, вимірювався артеріальний тиск, вимірювання життєвої ємності легенів, проводилася проба Штанге і оцінка рівня випробовується стресу (РВС) за індексом Шейх-Заде [34].

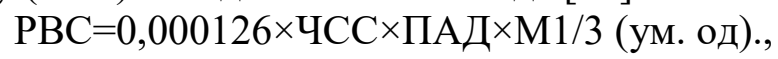

(де ЧСС - частота серцевих скорочень (уд/хв); ПАТ - пульсовий артеріальний тиск, що дорівнює різниці між максимальним і мінімальним тиском (мм рт. ст.); М - маса тіла).

Оцінка рівня стресу: 1,0-1,50 - норма, 1,51-2,00 - середній стрес, більше 2,00 виражений стрес.

Для статистичної обробки результатів дослідження була використана програма STATISTICA 6.0 (StatSoft, USA).

Результати і дискусія. Аналіз отриманих даних показав, що за період дослідження у школярів із затримкою психічного розвитку основної групи і групи порівняння відбулися різні зміни морфофункціонального стану (табл. 1 і 2).

Таблиия 1

Динаміка показників морфофункціонального стану хлопчиків 12-16 років із затримкою психічного розвитку за період дослідження

\begin{tabular}{|c|c|c|c|c|c|}
\hline \multirow{2}{*}{\multicolumn{2}{|c|}{ Показники }} & \multicolumn{2}{|c|}{ Основна група } & \multicolumn{2}{|c|}{ Група порівняння } \\
\hline & & до корекції & після корекції & до корекції & після корекції \\
\hline \multicolumn{2}{|c|}{ Маса тіла, кг } & $55,5+2,44$ & $58,7+2,33$ & $54,9+2,53$ & $57,7+2,45$ \\
\hline \multicolumn{2}{|c|}{ Зріст, см } & $168+1,58$ & $170+1,97$ & $166+2,13$ & $170+2,04$ \\
\hline \multirow{4}{*}{$\begin{array}{c}\text { Окружність } \\
\text { грудної } \\
\text { клітки, см }\end{array}$} & вдих & $78,4+2,36$ & $80,9+2,00$ & $77,5+2,21$ & $78,9+2,17$ \\
\hline & пауза & $74,9+2,23$ & $76,1+2,05$ & $74,1+2,16$ & $75,5+2,10$ \\
\hline & видих & $73,2+2,21$ & $73,6+2,03$ & $72,3+2,09$ & $73,6+2,12$ \\
\hline & екскурсія & $5,14+0,56$ & $7,29+0,24 *$ & $5,20+0,28$ & $5,31+0,21 * *$ \\
\hline \multicolumn{2}{|c|}{ ЧСС, уд/хв } & $83,2+1,90$ & $78,0+1,67$ & $82,3+1,98$ & $80,1+1,69$ \\
\hline \multirow{3}{*}{$\begin{array}{c}\text { Артеріальний } \\
\text { тиск (АТ), } \\
\text { мм рт.ст. } \\
\end{array}$} & CAT & $121+1,68$ & $116+0,89$ & $117+1,17$ & $118+1,27$ \\
\hline & ДАТ & $66,4+1,99$ & $74,1+0,89$ & $62,8+1,23$ & $69,5+1,14$ \\
\hline & ПАТ & $54,5 \pm 1,46$ & $41,9+0,54 *$ & $54,5+1,54$ & $48,8+1,40^{* * *}$ \\
\hline \multicolumn{2}{|c|}{ ЖЕЛ, мл } & $2738+83,8$ & $3329+78,6^{*}$ & $2708+96,8$ & $2923+97,7 * *$ \\
\hline \multicolumn{2}{|c|}{$\begin{array}{c}\text { Затримка дихання на } \\
\text { вдиху, с }\end{array}$} & $31,2+1,58$ & $56,2 \pm 1,26^{*}$ & $28,7+1,39$ & $36,4+1,03^{* *}$ \\
\hline
\end{tabular}

Примітка: * - достовірна різниця $(\mathrm{p}<0,05)$ між показниками до та після дослідження;

** - достовірна різниця $(\mathrm{p}<0,05)$ між показниками контрольної та експериментальної груп після дослідження.

Збільшення обсягу грудної клітки склало в групі 1,6\% на паузі у хлопчиків і 3,0\% - у дівчаток, на вдиху - 3,2\% і 0,5\% на видиху у школярів - на 4,3\% і 1,45\% - у школярок. У групі порівняння ці показники збільшилися відповідно на 1,8\%, 1,8\%, 1,7\% - у хлопчиків та на 2,0\%, 1,7\% і 2,1\% - у дівчаток відповідно. 
Динаміка показників морфофункціонального стану дівчат 12-16 років

Таблиия 2 із затримкою психічного розвитку за період дослідження

\begin{tabular}{|c|c|c|c|c|c|}
\hline \multirow{2}{*}{\multicolumn{2}{|c|}{ Показники }} & \multicolumn{2}{|c|}{ Основна група } & \multicolumn{2}{|c|}{ Група порівняння } \\
\hline & & до корекції & після корекції & до корекції & після корекції \\
\hline \multicolumn{2}{|c|}{ Маса тіла, кг } & $55,1+2,32$ & $57,8+2,33$ & $55,1+3,69$ & $57,4+3,66$ \\
\hline \multicolumn{2}{|c|}{ Зріст, см } & $165+3,59$ & $168+3,58$ & $166+2,54$ & $168+2,21$ \\
\hline \multirow{4}{*}{$\begin{array}{c}\text { Окружність } \\
\text { грудної клітки, } \\
\text { см }\end{array}$} & вдих & $82,1+3,64$ & $85,6+3,59$ & $80,9+4,37$ & $82,3+4,32$ \\
\hline & пауза & $78,9+3,69$ & $81,3+3,78$ & $78,3+4,48$ & $79,9+4,56$ \\
\hline & видих & $77,1+3,75$ & $78,3+3,8$ & $76,4+4,54$ & $77,7+4,47$ \\
\hline & екскурсія & $5,01+0,27$ & $7,38+0,38^{*}$ & $4,43+0,37$ & $4,57+0,30^{* *}$ \\
\hline \multicolumn{2}{|c|}{ ЧСС, уд/хв } & $81,4+2,21$ & $77,1+1,57$ & $81,3+2,37$ & $79,9+1,65$ \\
\hline \multirow{3}{*}{$\begin{array}{l}\text { Артеріальний } \\
\text { тиск (AT), } \\
\text { мм рт.ст. }\end{array}$} & CAT & $116+1,48$ & $113+1,64$ & $119+2,60$ & $115+1,89$ \\
\hline & ДАТ & $68,8+2,96$ & $71,3+0,82$ & $64,3+2,02$ & $64,3+2,02$ \\
\hline & ПАТ & $46,9+2,31$ & $41,3+1,57^{*}$ & $54,3+2,97$ & $50,7+1,70^{* *}$ \\
\hline \multicolumn{2}{|c|}{ ЖЕЛ, мл } & $2819+74,6$ & $3494+73,7^{*}$ & $2693+103,0$ & $2914+120,7 * *$ \\
\hline \multicolumn{2}{|c|}{ Затримка дихання на вдиху, с } & $34,9+2,91$ & $61,3+3,76^{*}$ & $33,4+2,89$ & $38,6+3,30^{* *}$ \\
\hline
\end{tabular}

Примітка: * - достовірна різниця $(\mathrm{p}<0,05)$ між показниками до та після дослідження; ** - достовірна різниця $(\mathrm{p}<0,05)$ між показниками контрольної та експериментальної груп після дослідження.

Значне і достовірне збільшення ( $<0,05)$ відзначено за показником екскурсії грудної клітини. Так, цей показник збільшується в основних групах на 41,8\% - у школярів і 47,6\% - у школярок. У групах порівняння екскурсія грудної клітки збільшується тільки на 1,9\% і 3,16\%. У процесі дослідження в усіх групах спостерігається незначне і статистично недостовірне зниження частоти серцевих скорочень, хоча в основних групах відсоток зміни цього показника дещо більше. Так, у хлопчиків 12-16 років із ЧСС знижується на 6,2\% і на 5,2\% - у дівчаток того ж віку. У групах порівняння цей показник зменшується на 2,7\% і 2,6\% відповідно. В кінці дослідження виявляється незначне зниження систолічного артеріального тиску, при одночасному збільшенні діастолічного тиску. При цьому в основних групах величина пульсового тиску статистично достовірно $(\mathrm{p}<0,05)$ наближається до фізіологічної норми. В основних групах систолічний артеріальний тиск зменшується на 4,1\% у школярів і на 2,7\% у школярок, діастолічний артеріальний тиск збільшується на $11,4 \%$ - у хлопчиків та $3,6 \%$ - у дівчаток. Пульсовий тиск знижується на 23,1\% і 12,0\%. У групах порівняння систолічний артеріальний тиск збільшується у хлопчиків - на 5,8\% і зменшується на $3,01 \%$ - у дівчаток. Діастолічний артеріальний тиск підвищується у школярів - на 10,8\% і не змінюється у школярок. Пульсовий тиск знижується відповідно на 10,55\% і 6,59\%. При цьому необхідно зазначити, що зміна артеріального тиску в групах школярів 12-16 років із затримкою психічного розвитку більш значна, ніж у групах школярок того ж віку.

У хлопчиків і дівчаток основних груп відзначені достовірні зміни $(\mathrm{p}<0,05)$ практично всіх досліджуваних показників зовнішнього дихання. Так, за період дослідження життєва ємкість легень збільшується на 21,6\% у школярів і 23,9\% у школярок. У дітей груп порівняння так само простежується деяка тенденція до поліпшення дихальних параметрів, однак відмінності в результатах тестування до і після експерименту незначні (p>0,05) i становлять 7,9\% i 8,2\% відповідно. Найбільший приріст у хлопчиків i дівчаток основних груп відбувся за часом затримки дихання на вдиху і склав 80,1\% і 75,6\%. У учнів груп порівняння цей показник так само збільшується на 27,1\% і 14,9\% відповідно. 
Тестування виявило значний вплив адаптивної корекційно-розвиваючої гімнастики на рівень стресу підлітків із затримкою психічного розвитку експериментальних груп (табл. 3).

Таблиия 3

Стан рівня досліджуваного стресу у школярів 12-16 років

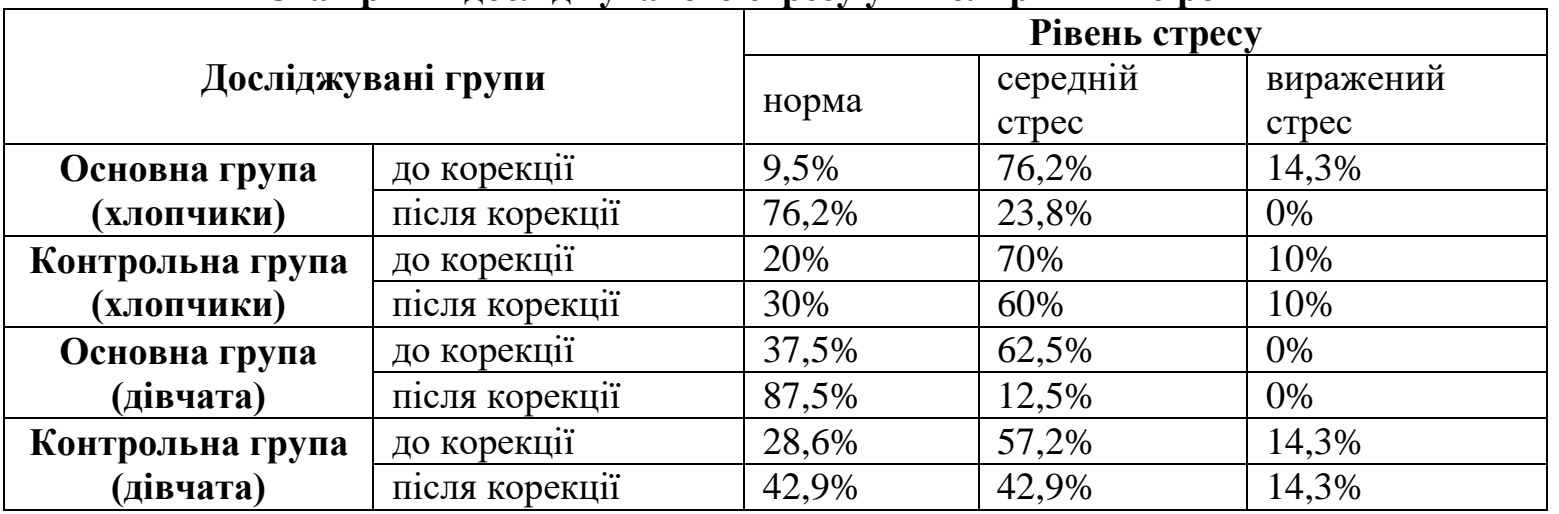

Кількість учнів із затримкою психічного розвитку основних груп, які відчувають в тій чи іншій мірі стрес, значно знижується. Так, частка школярів, що знаходяться в стані вираженого стресу знижується на $14,3 \%$ у хлопчиків, які відчувають помірне напруження механізмів адаптації (середній стрес) на 52,4\% в групі хлопчиків і на 50\% в групі дівчаток.

При цьому збільшується кількість школярів добре адаптованих до навчальної та побутової діяльності - на 66,7\% у хлопчиків і на 50\% у дівчаток. У контрольних групах також спостерігається тенденція до зменшення числа школярів, у яких спостерігається різне за ступенем напруження механізмів стресу та адаптації. Частка учнів, які відчувають виражений стрес, залишається незмінною як у хлопчиків, так і у дівчаток. Число учнів, які переживають стрес середньої сили, знижується на $10 \%$ - у хлопчиків та на 14,3\% - у дівчаток. При цьому паралельно збільшується кількість учнів, які не зазнають стресу на $10 \%$ і 14,3\% відповідно.

Таким чином, запропонована адаптивна корекційно-розвиваюча гімнастика виявилася ефективним засобом поліпшення морфофункціонального і психофізіологічного стану підлітків 12-16 років, що підтверджується отриманими в ході експерименту даними.

Висновки.

1. Підлітки з затримкою психічного розвитку мають більш низький рівень функціонування основних систем життєзабезпечення організму (відзначаються більш високі показники ЧСС і пульсового тиску, низькі показники екскурсії грудної клітини, життєвої ємності легень і часу затримки дихання на вдиху).

2. Заняття з адаптивної корекційно-розвиваючої гімнастики призводять до істотного покращення показників морфо-функціонального стану (збільшилися екскурсія грудної клітки на 41,8\% у хлопчиків і 47,6\% у дівчаток, життєва ємкість легень на $21,6 \%$ і 23,9\%; час затримки дихання на вдиху на 80,1\% і 75,6\% відповідно на тлі зниження пульсового тиску на 23,1\% у хлопчиків і $12,0 \%$ у дівчаток).

3. Під впливом адаптивної корекційно-розвиваючої програми кількість учнів із затримкою психічного розвитку основних груп, які відчувають в тій чи іншій мірі стрес, значно знижується. Так, частка школярів, що знаходяться в стані вираженого стресу знижується на 14,3\% у хлопчиків, які відчувають помірне напруження механізмів адаптації (середній стрес) на 52,4\% в групі хлопчиків і на 50\% в групі дівчаток. 
Подальші напрями досліджень необхідно спрямувати на розробку адекватних діагностичних та корекційних моделей для оптимізації фізичного розвитку, психологічного стану та соціалізації підлітків із затримкою психічного розвитку.

1. Боднар IP, Римар ОВ, Соловей АВ, Маланчук ГГ, Дацків ПП. Об'єктивні критерії для визначення функціонально-резервних можливостей учнів середнього шкільного віку. Педагогіка, психологія та медико-біологічні проблеми фізичного виховання і спорту.2015; (11): 11-19.

2. Засенко В, Колупаєва А. Діти з особливими потребами: пріоритетні напрями державної політики України в галузі освіти, соціального захисту й охорони здоров'я. Особлива дитина: навчання i виховання. 2014; 3(71): 20-29.

3. Пірожков СI. Демографічний фактор у глобальній стратегії розвитку України. Демографія та соціальна економіка. 2004; (1-2): 5-20.

4. Федосєєва ОА. Особливості ігрової діяльності дітей з інтелектуальною недостатністю. Молодий вчений. 2012;( 11): 489-491.

5. Hartley S, Newton CRJC. Children with developmental disabilities in the majority of the world. In: Shevell M, ed. Neurodevelopmental disabilities: clinical and scientific foundations. London, Mac Keith Press, 2009.

\section{References}

1. Bodnar IR, Rymar OV, Solovej AV, Malanchuk GG, Dackiv PP. Objektyvni kryterii dlja vyznachennja funkcionalno-rezervnych mozhlyvostej uchniv serednjogo shkilnogo viku [Objective criteria for determining the functional and reserve capabilities of pupils of secondary school age]. Pedagogika, psyhologia ta medyko-biologichni problem fizychnogo vyhovannja i sportu. 2015; (11): 1-19. [in Ukrainian]

2. Zasenko V, Kolupaieva A. Ditu z osoblivimi potrebami: prioritetni napriamy derzhavnoi politiky Ukrajiny v galuzi osvitu, socialnogo zahistu ta ohorony zdorovja [Children with special needs: priority directions of the state policy of Ukraine in the field of education, social protection and public health]. Osobliva ditina: navchannja i vihovannja. 2014; 3(7): 20-29. [in Ukrainian]

3. Pirozhkov SI. Demografichnyj factor u globalnyj strategiji rozvytku Ukrainy [Demographic factor in the global strategy of Ukraine's development]. Demografija ta socialna ekonomika. 2004; (1-2): 5-20. [in Ukrainian]

4. FedoseevaOA. Osoblivosti igrovoji dijalnosti ditej z intelektualnoju nedostatnistju [Features of the game activity of children with intellectual disabilities]. Mioloduj vchenij. 2012; (11): 489-481. [in Ukrainian]

5. Hartley S, Newton CRJC. Children with developmental disabilities in the majority of the world. In: Shevell M, ed. Neurodevelopmental disabilities: clinical and scientific foundations. London, Mac Keith Press, 2009. [in English].

\section{Цитування на цю статтю:}

Доцюк ЛГ, Гауряк ОД. Вплив адаптивної корекційно-розвиваючої програми на функціональний стан підлітків із затримкою психічного розвитку Вісник Прикарпатського університету. Серія: Фізична культура. 2019 Берез 26; 33: 34-39

\begin{tabular}{|c|c|}
\hline Відомості про автора: & Information about the author: \\
\hline $\begin{array}{l}\text { Доцюк Лідія Геораївна - доктор медичних наук, } \\
\text { професор, Чернівецький національний університет } \\
\text { імені Юрія Федьковича (Чернівці, Україна) }\end{array}$ & $\begin{array}{l}\text { Dotsiuk Lidiia Heorhiivna - Doctor of Medical } \\
\text { Science, Professor, Yuriy Fedkovych Chernivtsi Natio- } \\
\text { nal University (Chernivtsi, Ukraina) }\end{array}$ \\
\hline \multicolumn{2}{|c|}{$\begin{array}{l}\text { e-mail: lgdotsyuk@gmail.com } \\
\text { https://orcid.org/0000-0002-1298-4428 }\end{array}$} \\
\hline $\begin{array}{l}\text { Гауряк Олена Дмитрівна - кандидат педагогічних } \\
\text { наук, Чернівецький національний університет імені } \\
\text { Юрія Федьковича (Чернівці, Україна) }\end{array}$ & $\begin{array}{l}\text { Hauriak Olena Dmytrivna - Candidate of Science } \\
\text { (Education), Yuriy Fedkovych Chernivtsi National } \\
\text { University (Chernivtsi, Ukraina) }\end{array}$ \\
\hline $\begin{array}{l}\text { e-mail: olena.hauriak@ gmail.com } \\
\text { https://orcid.org/0000-0002-2354-7012 }\end{array}$ & \\
\hline
\end{tabular}

